\title{
Influence of intermittent and continuous microwave heating on drying kinetics and wood behavior of Eucalyptus Gomphocephala
}

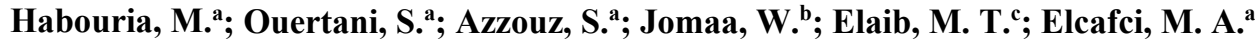 \\ ${ }^{a}$ Laboratoire d'Energétique et des Transferts Thermique et Massique, Département de Physique, \\ Faculté des Sciences de Tunis, University of Tunis El Manar. \\ ${ }^{b}$ Institut de Mécanique et d'Ingénierie de Bordeaux, University of Bordeaux \\ ${ }^{\mathbf{c}}$ Laboratoire de Gestion et de Valorisation des Ressources Forestières. INRGREF, University of \\ Carthage
}

*E-mail of the corresponding author: mariam.habouria@gmail.com

\begin{abstract}
The aim of this work was to determine the microwave drying kinetics of Eucalyptus Gomphocephala wood and to investigate the influence of intermittent and continuous heating processes on the end quality of dreid samples. The average moisture content evolution and temperature of wood samples under different microwave powers were analyzed in terms of drying time and internal temperature level. Results show that the increase of microwave power level decreses the drying time and increases the internal wood temperature. Based on qualitative observations on the state of dried samples, the intermittent microwave powers intensity process present the optimal processing parameter in microwave drying of Eucalyptus wood species.
\end{abstract}

Keywords: microwave drying; power; intermittent; continuous; Eucalyptus wood. 


\section{Introduction}

Drying is an operation process consisting of the removal or reduction of water from a product. This process is often used as a final production step before selling or packaging products, especially wood, to ensure its structural stability, to remove fungal attacks and to improve its mechanical performance... There are different methods of drying wood, and the majority of industrial dried timber is processed with convective drying. This conventional drying of wood is slow and costly process [1]. For that reason, interest is oriented to study the electro heating technology of wood, in particular, microwave energy for specific applications in the wood industry to achieve specific objectives, such as reducing the drying time and energy consumption, accelerate internal transfers of mass and heat and providing good mechanical properties with high strength $[2,3]$.

The principle of microwave heating is based on the concept of internal generation of heat. If wood is exposed to an electromagnetic field with such high frequency as is characteristic for microwave, the water molecules, which are dipoles, begin to rotate at the same frequency as the electromagnetic field. At a frequency of $2.4 \mathrm{GHz}$ the alternating electric field component oscillates very quickly and the strong agitation, provided by cyclic reorientation of molecules, produce friction of water molecules can result in an intense internal heating of wood $[3,4]$. The interaction between microwave and wood material depends on power and frequency of microwave oven, on geometric and dimensions of the wood sample, on water content and the dielectric properties [4]. During drying, moisture, temperature, and gas pressure gradients involve product shrinkage and then development of strain and stress fields inside the Eucalyptus wood samples. So, the quality of drying of eucalyptus wood vary according to the type of microwave drying. According to our bibliographic research, few published works concerning the impact of microwave heating on qualitative behavior of dried Eucalyptus wood and no information about Gomphocephala wood has been published, and there is a lack of information on the continuous and intermittent microwave heat treatment of Eucalyptus wood. Intermittent drying is based on oscillating of operation conditions such as the temperature, relative humidity, speed of the air flow... This technique should make it possible to relax some of the mechanical stress induced by drying inside the material [5]. Microwave drying under controlling conditions has been the subject of some research works. Lars H. [6] has shown that microwave drying under controlled temperature conditions reduces internal stress and prevents checks of samples. L. Hansson, A.L. Antti (a) [7] showed that controlled microwave drying can improve a better wood resistance in a shorter drying time and the results are comparable to those obtained by conventional drying. In addition, Bruno Monteiro Balboni et al [8] have shown that drying at high microwave power produces reductions of wood strength and more drying defects than low microwave power. The 
present work is particularly interested in the microwave drying of Eucalyptus wood (Gomphocephala) from the northeastern region of Tunisia. Kinetics of intermittent and continuous microwave drying of wood sample under different microwave power were analyzed in order to determine the drying temperatures levels and to evaluate the potential of microwave irradiation on the final behavior of dried wood.

\section{Materials and Methods}

\subsection{Eucalyptus wood (Gomphocephala)}

Eucalyptus trees are characterized by their ecological plasticity and their rapid growth. It covers 18 million ha in 90 countries in the world. Eucalyptus is mainly used in the wood industry and it is also used as an energy source or in building. Previous studies have shown that Eucalyptus wood has a specific sensitivity during final drying as collapse, cracks and warps [9]. The samples of green Eucalyptus wood used in this work were recommended by the INRGREF. The samples are rectangular $(30 * 5 * 2 \mathrm{~cm} 3)$ size boards, sawn in the fibers direction (longitudinal direction) and have an initial average moisture content of 52\%, (Fig.1). The mass of dry wood was obtained after keeping the samples in a controlled temperature oven at $103^{\circ} \mathrm{C}$ until a constant mass was reached. These samples are wrapped with cellophane paper and stored in a refrigerator until the date of the experiments to retain their green state properties. The drying conditions achieved are presented in (Table 1).
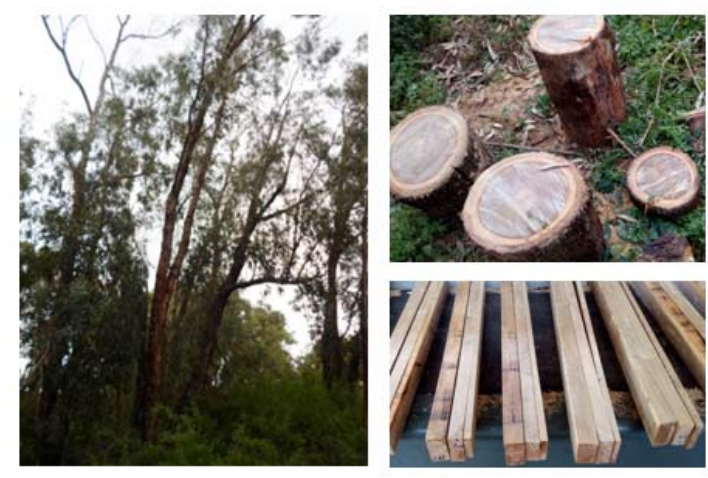

Fig.1 Eucalyptus tree (Gomphocephala): region of Oued Ksab, Tunis, Tunisia.

Table 1: Parameters of continuous and intermittent microwave heat treatment for different microwave power.

\begin{tabular}{|c|c|c|c|c|c|}
\hline \multirow{2}{*}{$\begin{array}{l}\text { Drying } \\
\text { conditions }\end{array}$} & \multirow{2}{*}{$\begin{array}{c}\text { Microwave } \\
\text { power (Watt) }\end{array}$} & \multirow{2}{*}{$\begin{array}{l}\text { Continuous } \\
\text { drying (min) }\end{array}$} & \multicolumn{3}{|c|}{ Intermittent drying (min) } \\
\hline & & & Total drying & Microwave drying & $\begin{array}{l}\text { One complete } \\
\text { "on -off" cycle }\end{array}$ \\
\hline $\mathrm{P}_{1 \max }$ & 300 & 95 & 1020 & 780 & 7 \\
\hline $\mathrm{P}_{2 \max }$ & 500 & 40 & 736 & 363 & 15 \\
\hline $\mathrm{P}_{3 \max }$ & 1000 & 12 & 445 & 180 & 25 \\
\hline
\end{tabular}




\subsection{Drying unit: Laboratory Microwave oven}

The experimental setup used in this work is a laboratory microwave oven (Fig.2) with a working cavity of $34 \times 33 \times 20 \mathrm{~cm} 3$, a relative humidity ranging from 10 to $90 \%$ and a vapor extracting system. This microwave oven operating at $2.45 \mathrm{GHz}$ frequency is able to provide a maximum power of $1000 \mathrm{~W}$. During the drying process, the lumbers were placed at the center of the drying chamber and removed periodically to measure their mass. The wood temperature is also measured during the experiment. The product moisture content in the dry basis ( $\mathrm{kg}$ of water/ $\mathrm{kg}$ of dry matter) is calculated according to the following relationship:

$$
\mathrm{M}(\%)=\frac{\mathrm{W}-\mathrm{W}_{\mathrm{d}}}{\mathrm{Wd}} \times 100=\frac{\mathrm{W}_{\text {water }}}{\mathrm{W}_{\mathrm{d}}} \times 100
$$

The moisture content ratio was given by the following equation:

$$
\mathrm{MR}=\frac{\mathrm{M}}{\mathrm{M}_{\mathrm{ini}}}
$$

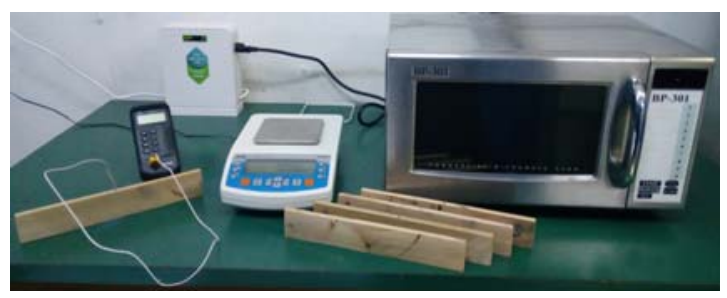

Fig.2: Laboratory microwave oven BP-301.

\section{Results and discussion}

\subsection{Kinetics of continuous and intermittent microwave drying}

The effect of microwave power on the evolution of the average moisture content of Eucalyptus wood (Gomphocephala) is shown in (Fig.3). For both kinds of drying an increase of microwave power decreases the drying time and increases both the core temperature and therefore the internal gas pressure of wood sample.

Figure4 shows the simultaneous evolution of the average moisture content and the temperatures of the top surface, the bottom surface and the center of the wood during for a continous microwave drying at a high level of microwave power. The beginning corresponds to a warming phase where temperature evolves quickly and water content drops slightly. The second phase corresponds to a vaporization phase where temperature is mostly constant near $100^{\circ} \mathrm{C}$ and water content decreases rapidly. The third phase is the 
heating one, where the loss of water slows down and the temperature of the wood increases. This behavior is similar to those observed by other researchers [10].

\subsection{Influence of continuous and intermittent process on final quality of dried wood}

At this section we will focus on qualitative evaluation of the impact of continuous and intermittent heat treatment on the final quality of dried Eucalyptus wood. The adopted approach is based on qualitative observations on the final state of the dried wood in terms of deformations, warping, slits, checks, splits and colorations.
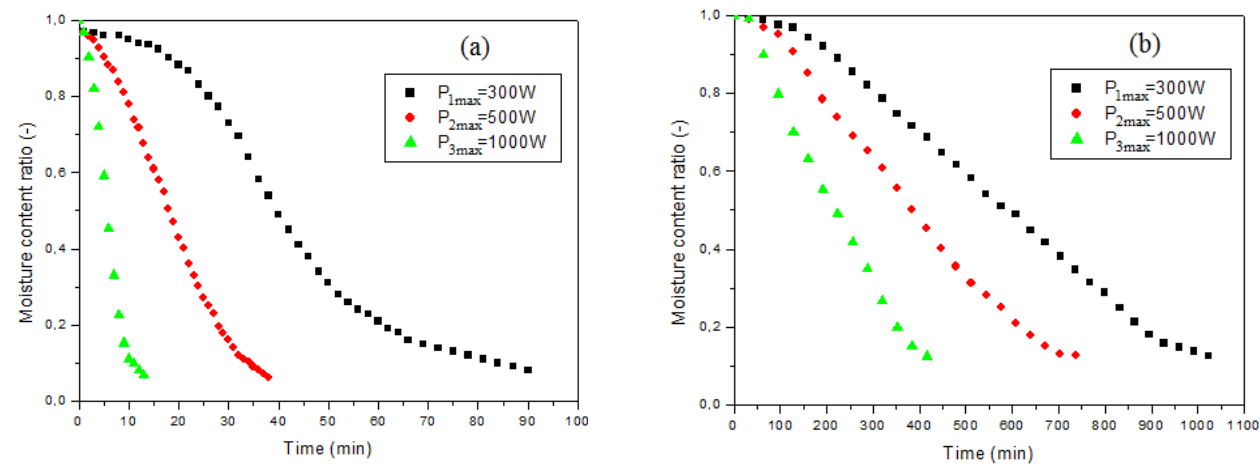

Fig.3: Moisture content versus time for different drying conditions.(a) continuous drying;

(b) intermittent drying.

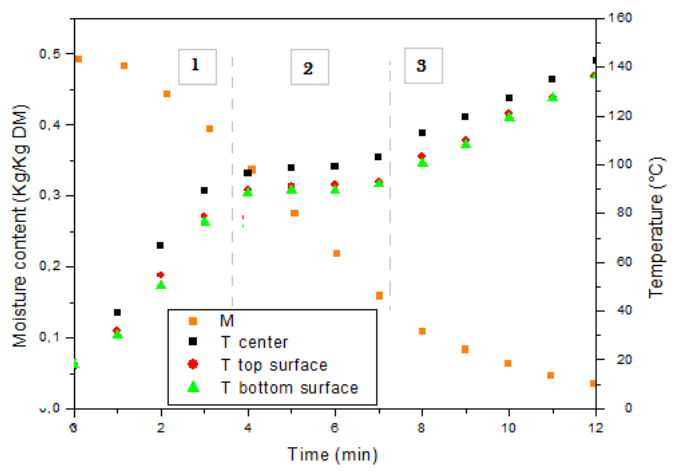

Fig.4: Core and surfaces temperature and moisture content versus time at high microwave power.

These observations are illustrated by photos of the wood samples relating to each type of drying achieved. Figure5 shows the wood sample dried continuously under high microwave power $(1000 \mathrm{~W})$. After $12 \mathrm{~min}$ of drying, the black color appears indicating a carbonization of the ligneous material of the wood. 


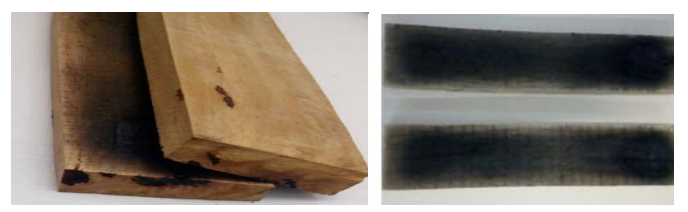

Fig.5: Effect of continuous microwave drying of wood at a maximum power (1000 W).

In addition, the darkening is located in the center of the plate illustrating the intense internal volumetric heating in the case of microwave heat treatment [11]. In the case of of continous drying process under 500 Watts of microwave power, these defects are observed at the end of drying (Fig.6).
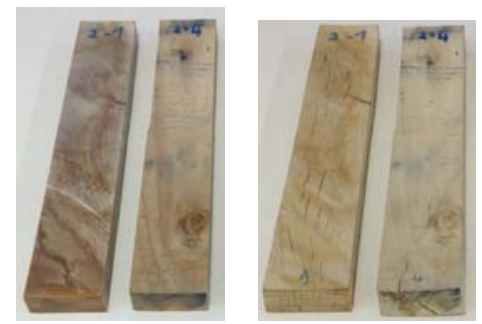

Fig.6: Effect of continuous microwave drying of wood at $500 \mathrm{~W}$; Before and after drying.

During a rapid drying at high microwave power, an over gas pressure is generated under the increasing of internal temperature of wood. The temperature increases continuously (up to $120^{\circ} \mathrm{C}$ ) and passes through the boiling point of water and the resultant intense internal gas pressure pushes the water, so the mixture of water and gas will be forced out from the wood. Indeed, the high microwave power generate the over gas pressure inside the wood, which can break some intercellular bonds and causes internal checks, cracks and fissures in the wood structure. In order to avoid the problems related to the overpressure of the internal gas and the carbonization of wood material due to high temperatures, it is necessary to apply relatively low microwave power. Also, under the low microwave power 300 Watts we abserved the warping of the wood samples at the end of the continuous drying process (Fig.7). Indeed, temperature increases on the board surface. The degradation occurs in wood heated above $100^{\circ} \mathrm{C}$, and can affect the chemical constituents of the cell wall or cause major structural damage. This efect was already observed by Eva Hermoso et al.[12].

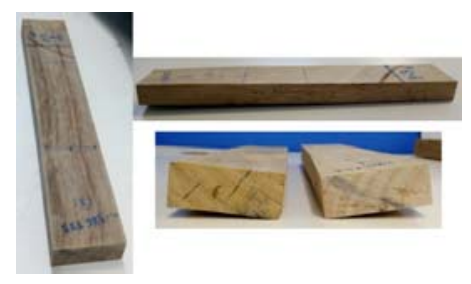

Fig.7: Effect of continuous microwave drying of wood at $300 \mathrm{~W}$ of power; Before and after drying. 
The second solution proposed in this study is to apply an intermittent drying process. This process is only considered at the microwave power level, and the conditions of drying are shown in (Table 1). The qualitative observations are illustrated by the photos of dried wood samples, (Fig.8). It is observed that drying defects related to the level of microwave power in the continuous drying are absent in the intermittent drying. The absence of the various defects can be explained by the cooling of wood sample and mechanical stress relaxation during the intermittency phase.

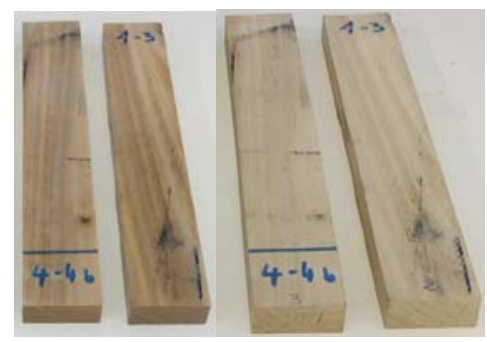

Fig.8: Effect of intermittent microwave drying of wood at $500 \mathrm{~W}$; Before and after drying.

One can notice that oscillation of the microwave power between 0 and $\mathrm{P}_{\max }$ increases drying time compared to continuous drying (See Figure 3) but allows to reduce average temperature and internal gaz phase. The optimization of the intermittency phases make it possible to optimize drying in terms of drying time and wood quality.

\section{Conclusions}

The experimental results indicated that increasing the microwave power decreases the drying time and increases both the core temperature and the internal gas pressure of wood samples. The phenomenon of internal heat generation during microwave drying wood was verified by the temporal evolution of temperature curves. A qualitative analysis of dried wood samples proves that the intermittent microwave drying reduces the defects related of drying and improved product quality compared with continuous microwave drying. As an extension of this work, mechanical tests of axial compression and static bending strength will be held. Optimization of intermittency phases will be also carried by the help of modelling heat, mass and mechanical behavior of wood sample on intermittent microwave drying.

\section{Nomenclature}

$\begin{array}{lll}\mathrm{P} & \text { Microwave power } & \text { Watt } \\ \mathrm{T} & \text { Temperature } & { }^{\circ} \mathrm{C} \\ \mathrm{W} & \text { Wood sample mass } & \mathrm{kg} \\ \mathrm{W}_{\text {water }} & \text { Water mass } & \mathrm{kg} \\ \mathrm{W}_{\mathrm{d}} & \text { Wood sample dry mass } & \mathrm{kg} \\ \mathrm{M}_{\text {ini }} & \text { Initial moisture content } & \mathrm{kg} \text { water } / \mathrm{kg} \mathrm{DM}\end{array}$




\section{Acknowledgments}

Our thanks go to Abderrazak Zaaraoui from the LETTM, Sara Ghariani from INRGREF and for both of Sameh Hannachi and alaeddine garali from CETIBA for their technical assistance and help in carrying out the experiments.

\section{References}

[1] S. Ouertani, A. Kouba, S. Azzouz, L. Hassini, K. Ben Dhib, A. Belghith, Vacum contact drying kinetics of Jack pine wood and its influence on mechanical properties : industrial applications, Heat Mass Transf.DOI 10.1007/s00231-014-1476-0, 2014.

[2] Turner, I.W.; Puiggali, J.R.; Jomaa, W. A numerical investigation of combined microwave and convective drying of a hygroscopic porous material. A study based on pine wood. Chemical Engineering Research \& Design 1998, 76, 193-209.

[3] S. Ouertani, L. Hassini, S. Azzouz, S.S. Torres, A. Belghith, A. Koubaa, Modeling of combined microwave and convective drying of wood: Prediction of mechanical behavior via internal gas pressure, Drying Technology, ID: 1022828 DOI:10.1080/07373937.2015.1022828, 2015.

[4] F. Erchiqui, 3d numerical simulation of thawing frozen wood using microwave energy: frequency effect on the applicability of the beer-lambert law, Drying Technology, Volume 31, Pages 1219-1233, 2013.

[5] Thouraya Salem. Séchage intermittent du bois d'oeuvre : étude expérimentale et numérique. Matériaux. Université de Lorraine, 2016. Français. <NNT : 2016LORR0177>.

[6] Lars Hansson, Microwave Treatment of Wood. University of Technology LTU Skelleftea Division of Wood Physics, 2007.

[7] L. Hansson et A.L. Antti (a). The effect of microwave drying on Norway spruce woods strength: a comparison with conventional drying. Journal of Materials Processing Technology 141 (2003) 41-50

[8] Bruno Monteiro Balboni et al. Microwave treatment of Eucalyptus macrorhyncha timber for reducing drying defects and its impact on physical and mechanical wood properties. Eur. J. Wood Prod. DOI 10.1007/s00107-017-1260-1

[9] Ihsane LOULIDI et al. Impact energy on notched and unnotched specimens of wooden Eucalyptus Gomphocephala under variation of moisture. Sciences et Technologie B - Nº36, (Décembre 2012), pp 9-14.

[10] G. Du, S. Wang, Z. Cai, Microwave drying of wood strands, Drying Technology, Volume 23, Pages 1-16, 2005.

[11] Lars Hansson, Microwave Treatment of Wood. University of Technology LTU Skelleftea Division of Wood Physics, 2007.

[12] Eva Hermoso, Abel Vega. Effect of microwave treatment on the impregnability and mechanical properties of Eucalyptus globulus wood. Maderas. Ciencia y tecnología 18(1): 55 - 64, 2016 